\title{
Effect of Rehabilitation Team Meeting on the Patient's Disability in the Department of Physical Medicine and Rehabilitation (PMR) in a Tertiary Care Hospital in Dhaka
}

\author{
Shoma $\mathrm{FK}^{1^{*}}$, Uddin $\mathrm{MT}^{1}$, Emran MA ${ }^{1}$, Islam $\mathrm{MT}^{1}$, Ahmed B ${ }^{1}$, Chowdhury ZR ${ }^{1}$ \\ ${ }^{I}$ Department of Physical Medicine and Rehabilitation (PMR), Bangabandhu Sheikh Mujib Medical \\ University (BSMMU), Dhaka, Bangladesh
}

\begin{abstract}
Background: Teamwork is one of the most fundamental factors in rehabilitation medicine. Although isolated physicians and therapists are working with rehabilitation services in Bangladesh, there is limited data for understanding the effects of a team effort.
\end{abstract}

Objective: To evaluate the effect of rehabilitation team meeting on the patients' disability in the Department of Physical Medicine and Rehabilitation (PMR) in Bangabandhu Sheikh Mujib Medical University (BSMMU), Dhaka.

Methods: This was a randomized controlled trial conducted in the Department of Physical Medicine and Rehabilitation (PMR) in Bangabandhu Sheikh Mujib Medical University (BSMMU), Dhaka from September 2018 to October 2019. Two hundred and thirty nine patients attending the PMR department for comprehensive management of disability (such as disability in mobility, speech, self-care, sphincter control etc.) were purposively selected for the study. Patients were randomly allocated by lottery in two groupsgroup A (received Rehabilitation Team Meeting service) and group B (received conventional Rehabilitation treatment). The meeting comprised physiotherapist, occupational therapist, rehabilitation nurse, speech and language therapists, social worker, nutritionist, psychologists under the team leader guidance by physiatrist. Respondents of both groups were assessed to see the effects of treatment at $6^{\text {th }}$ weeks, $12^{\text {th }}$ weeks and $24^{\text {th }}$ weeks. Among 239 patients, 77 patients in group A and 71 patients in group B had completed $24^{\text {th }}$ week follow up. Outcomes were measured by FIM (Functional independence Measure) scores.

Results: The mean age of the patients in group A and B were $42.2( \pm 17.5)$ years and $45.7( \pm 14.6)$ years respectively. In both groups, majority of the patents were male and came from urban areas. Main cause of disability was stroke while others had traumatic brain injury, spinal cord injury, spinal cord compression, rheumatoid disease and others. At baseline and after $6^{\text {th }}$ week of treatment, there were no significant statistical differences between the two groups $(p>0.05)$ regarding FIM scores. In $12^{\text {th }}$ week, FIM significantly increased in group A $(p=0.009)$ compared to group B which persisted till $24^{\text {th }}$ week $(p<0.001)$.

Conclusion: Rehabilitation team meeting significantly reduce disability of the patient. It needs to work continuously to build up the rehabilitation team to improve physical rehabilitation in Bangladesh to ensure total care of the disabled.

Keywords: Rehabilitation, Team meeting, Functional independence measure (FIM), Physical medicine

\section{Introduction}

With the rising prevalence of non-communicable diseases and injuries and the ageing population, there is a substantial and ever-increasing unmet need for rehabilitation. Rehabilitation is a set of interventions designed to optimise functioning and reduce disability in individuals with health conditions in interaction with their environment. ${ }^{1}$ Patients undergoing comprehensive rehabilitation require the services of multiple health care

*Correspondence: Dr. Farzana Khan Shoma, Department of Physical Medicine and Rehabilitation (PMR), Bangabandhu Sheikh Mujib Medical University (BSMMU), Dhaka, Bangladesh.

e-mail: farzanadmck53@gmail.com; ORCID: 0000-0002-5355-490x providers who possess unique skills, training, and expertise that are employed for the full restoration of these patients' function and their optimal reintegration into all aspects of life. Assessment, treatment planning, and therapy are often provided by rehabilitation clinicians specialising in occupational therapy, physical therapy, prosthetics and orthotics, psychology and recreational therapy, speech and language pathology, rehabilitation nursing, social work, dietary science, case management, and others. ${ }^{2}$

Teamwork is one of the most fundamental factors in rehabilitation medicine. ${ }^{3}$ Team interaction is associated with an improvement in treatment 
outcomes and a reduction of morbidity, as well as an increase in patient satisfaction, employee satisfaction and a reduction of health economic costs. ${ }^{4-7} \mathrm{~A}$ recent study showed that following a team meeting template in an inpatient stroke rehabilitation program led to an increased home discharge rate. ${ }^{8}$

Disability remains a neglected issue and person with disability face multiple barriers in Bangladesh. ${ }^{9}$ The reported disability prevalence in Bangladesh varies widely from $5.6 \%$ to $16.2 \% .{ }^{10}$ Physical, psychosocial, visual, speech, intellectual, hearing, and hearing-visual disability, autism, cerebral palsy, Down syndrome, and multiple disabilities all exist in Bangladesh, of which physical disabilityis the most prevalent $(22.5 \%){ }^{9}$

Bangladesh, as 1 of the 194 United Nations member states, endorsed the World Health Organization (WHO) global disability action plan (GDAP) 2014 to2021. ${ }^{11}$ There stands a necessity of developing a better service outlet of the patients with pain and paralysis in association of various disabilities.

Rapidly expanding Bangabandhu Sheikh Mujib Medical University (BSMMU) has been working as the centre of excellence for patient managements and postgraduate medical education in Bangladesh. Rehabilitation medicine indoor services was started during June 2015 and over a total of 600 patients were treated in the facilities so far. Although isolated physicians and therapists are working with rehabilitation services, there is limited data for understanding effects of a team effort. BSMMU has started Rehabilitation Team Meeting in $18^{\text {th }}$ September 2018 to reduce disability of the patients through team work. This rehabilitation team consist of a physiotherapist (PT), occupational therapist (OT), speech language therapist (SLT), rehabilitating nurse, nutritionist, $\mathrm{P} \& \mathrm{O}$ specialist, and residents from psychiatry facilitated by senior faculties of rehabilitation and PMR residents. The present study evaluated the effect of rehabilitation team meeting on the patient's disability attending in the Department of Physical Medicine and Rehabilitation (PMR) in BSMMU.

\section{Materials and Methods}

Research design: This randomized controlled trial was conducted in the Department of Physical Medicine and Rehabilitation, BSMMU from September 2018 to October 2019. Purposive sampling technique was applied to select research participants. The inclusion criteria for patients selection was disability in mobility, speech, selfcare, sphincter control etc. Patients suffering from stroke, spinal cord injury, traumatic brain injury, transverse myelitis, cerebral palsy, motor neuron disease, Parkinson's disease were also included in the study. Patients with history/ evidence of acute swollen joint (septic arthritis), recent trauma, fracture, unstable joint, contagious skin infection and having recent heart attack or Pott's disease were excluded from the study.

Patients were randomly allocated by lottery in two groups. The meeting was held once in a week. The meeting comprised physiotherapist, occupational therapist, rehabilitation nurse, speech and language therapists, social worker, nutritionist, psychologists under the team leader guidance by physiatrist. In each meeting, two to four patients who met the inclusion criteria were selected and treatment was given. Besides these, follow up was also given to old patients. Patients were enrolled for six months. Within these six months, 89 patients were enrolled. This group was named as group A. Simultaneously, 89 patients were enrolled for conventional Rehabilitation treatment. This group was named as group B.

All patients were enrolled after having informed written consent and were evaluated by history taking, physical examination and relevant investigations. Respondents of both groups were assessed to see the effects of treatment at $6^{\text {th }}$ weeks, $12^{\text {th }}$ weeks and $24^{\text {th }}$ weeks. Among the 239 patients, 77 patients in group and 71 patients in group B had completed $24^{\text {th }}$ week follow up.

Outcome measures: Outcomes were measured by FIM (Functional independence Measure) scores. ${ }^{12}$

Data processing and analysis: The statistical analysis was conducted using SPSS (statistical package for social science) version 25 statistical software. Associations of categorical data were assessed using Chi-square test. Associations of continuous data were assessed using student t- test. For both test, $p<0.05$ was considered significant.

Ethical implication: Ethical clearance was taken from Institutional Review Board (IRB) of BSMMU. Informed written consent was taken from every patient before enrollment.

\section{Results}

In group A, 19 (24.7\%) patients were from 21-40 years age group and $33(42.9 \%)$ patients were from 41-60 years age group while in group B, 14 (19.7\%) patients were from $21-40$ years age group 
and $42(59.2 \%)$ patients were from 41-60 years age group. In both groups, majority of the patents were male and came from urban areas. In group A, 23 (29.9\%) patients were service holder and others were housewives $(24.7 \%)$, students $(18.2 \%)$, and businessmen (14.3\%) while in group B, 27 $(38.0 \%)$ patients were service holder and others were housewives $(22.5 \%)$, students $(14.1 \%)$, and businessmen $(15.5 \%)$. No significant statistical difference was seen regarding age, gender, residence and occupational status between the groups as the $p$-value was $>0.05$ (table I).

Table I: Socio-demographic characteristics of patients

\begin{tabular}{|c|c|c|c|}
\hline $\begin{array}{l}\text { Socio-demographic } \\
\text { characteristics }\end{array}$ & $\begin{array}{l}\text { Group A } \\
(\mathrm{n}=77)\end{array}$ & $\begin{array}{l}\text { Group B } \\
(n=71)\end{array}$ & $P$ value \\
\hline \multicolumn{4}{|l|}{ Age (in years) } \\
\hline Up to 20 & $14(18.2 \%)$ & $6(8.5 \%)$ & \multirow{4}{*}{0.172} \\
\hline $21-40$ & $19(24.7 \%)$ & \multirow{3}{*}{$\begin{array}{l}14 \\
(19.7 \%) \\
42 \\
(59.2 \%) \\
9(12.7 \%)\end{array}$} & \\
\hline $41-60$ & $33(42.9 \%)$ & & \\
\hline$>60$ & $11(14.3 \%)$ & & \\
\hline Mean \pm SD & $\begin{array}{l}42.21 \\
\pm 17.53 \\
\end{array}$ & $\begin{array}{l}45.66 \\
\pm 14.59 \\
\end{array}$ & \\
\hline \multicolumn{4}{|l|}{ Gender } \\
\hline Male & $51(66.2 \%)$ & $\begin{array}{l}48 \\
(67.6 \%)\end{array}$ & \multirow[t]{2}{*}{0.859} \\
\hline Female & $26(33.8 \%)$ & $\begin{array}{l}23 \\
(32.4 \%) \\
\end{array}$ & \\
\hline \multicolumn{4}{|l|}{ Residence } \\
\hline Rural & $17(22.1 \%)$ & $\begin{array}{l}15 \\
(21.1 \%)\end{array}$ & \multirow[t]{2}{*}{0.888} \\
\hline Urban & $60(77.9 \%)$ & $\begin{array}{l}56 \\
(78.9 \%) \\
\end{array}$ & \\
\hline \multicolumn{4}{|l|}{$\begin{array}{l}\text { Occupational } \\
\text { status }\end{array}$} \\
\hline Service holder & 23 (29.9) & $27(38.0)$ & \multirow{5}{*}{0.821} \\
\hline House wife & $19(24.7)$ & $16(22.5)$ & \\
\hline Student & $14(18.2)$ & $10(14.1)$ & \\
\hline Businessman & $11(14.3)$ & $11(15.5)$ & \\
\hline $\begin{array}{l}\text { Retired person and } \\
\text { others }\end{array}$ & $10(13.0)$ & $7(9.9)$ & \\
\hline
\end{tabular}

In group A, patients had disability mainly due to stroke $(36.4 \%, \mathrm{n}=28)$ while others had disability due to traumatic brain injury $(28.6 \%, \mathrm{n}=22)$, spinal cord injury $(15.6 \%, \mathrm{n}=12)$, spinal cord compression $(13.0 \%, \mathrm{n}=10)$, rheumatoid disease and others $(6.5 \%, \mathrm{n}=5)$. In group $\mathrm{B}$, patients also had disability mainly due to stroke $(42.3 \%, \mathrm{n}=30)$ while others had disability due to traumatic brain injury $(21.1 \%$, $\mathrm{n}=15)$, spinal cord injury $(15.5 \%, \mathrm{n}=11)$, spinal cord compression $(12.7 \%, \mathrm{n}=9)$, rheumatoid disease and others $(8.5 \%, \mathrm{n}=6)$ (figure 1$)$.

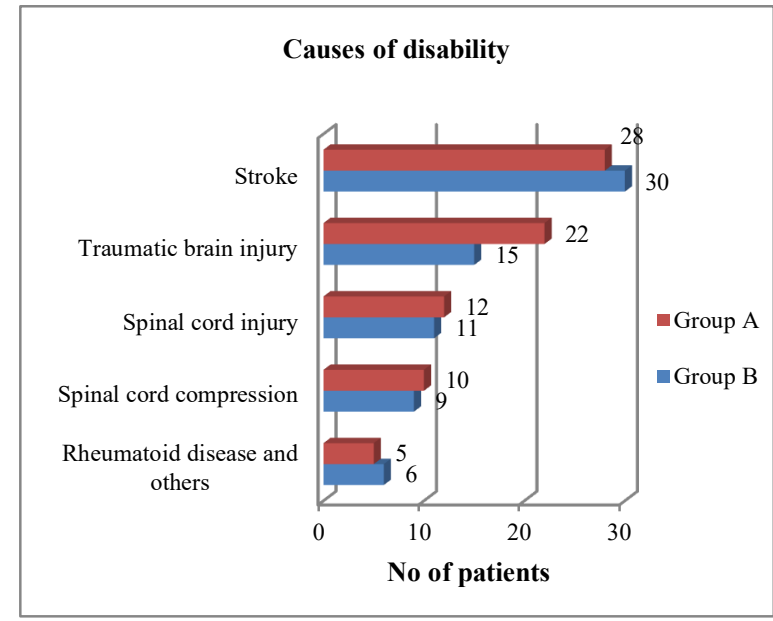

Figure 1: Distribution of patients by causes of disability

At baseline and after $6^{\text {th }}$ week of treatment, there were no significant statistical differences between the two groups $(p>0.05)$ regarding FIM scores. In $12^{\text {th }}$ week, FIM significantly increased in group A $(p=0.009)$ compared to group B which persisted till $24^{\text {th }}$ week $(p<0.001)$ (table II).

Table II: Comparison of patients by FIM scores

\begin{tabular}{|c|c|c|c|}
\hline FIM score & Group A & Group B & $p$ value \\
\hline At baseline & $\begin{array}{c}77.89 \pm \\
14.39\end{array}$ & $76.22 \pm 12.95$ & 0.767 \\
\hline At $6^{\text {th }}$ week & $\begin{array}{c}83.58 \pm \\
13.06\end{array}$ & $82.24 \pm 12.07$ & 0.517 \\
\hline At $12^{\text {th }}$ week & $99.73 \pm 8.61$ & $95.52 \pm 10.80$ & 0.009 \\
\hline At $24^{\text {th }}$ week & $\begin{array}{c}110.14 \pm \\
8.38\end{array}$ & $98.56 \pm 11.21$ & $<0.001$ \\
\hline
\end{tabular}

\section{Discussion}

Rehabilitation is an essential part of the continuum of care, along with prevention, promotion, treatment and palliation, and should therefore be considered an essential component of integrated health services. ${ }^{1} \mathrm{~A}$ German study suggests that high patient satisfaction and treatment acceptance is better predicted by positive team interactions, in addition to good physician-patient communication. ${ }^{13}$ The present randomized controlled trial evaluated the effect of rehabilitation team meeting on the patient's disability attending in the Department of Physical Medicine and Rehabilitation (PMR) in BSMMU.

According to Population monograph of Bangladesh, the prevalence of disability was reported to higher among the older people compared to the younger people. ${ }^{14}$ The result of the present study found that a significant number of patients were from 41-60 years age group. In both groups, majority of the patents were male. As, road traffic accident is one of the main cause of disability 
in Bangladesh and male have to move on road more, the proportion of male patients were more in the present study. ${ }^{10}$

Majority of the patents came from urban areas. However, the population monograph of Bangladesh 2015 found that disability is more prevalent in rural area compared to urban area. ${ }^{14}$ The dissimilarity of result might be due to the fact that BSMMU is situated in the capital of Bangladesh were urban patients come more frequently than rural areas while the BBS report engaged people of whole Bangladesh.

Road traffic accidents are the leading cause of trauma in Bangladesh. ${ }^{15}$ The present study also found that majority of the patients in both groups had injuries (traumatic brain injuries and spinal cord injuries) which was mainly caused by road traffic accidents. A significant number of patients had disabilities due to stroke. Stroke is a major public health problem in Bangladesh in which male and elderly people mainly suffered. ${ }^{16}$

All of the patients in both groups were followed-up for 24 weeks. Within these period, patients of the team meeting group came in close contact with the members of the team. Though up to $6^{\text {th }}$ week of treatment, there were no significant statistical differences between the two groups regarding FIM scores, in $12^{\text {th }}$ week, FIM significantly increased in group team meeting group compared to other which persisted till $24^{\text {th }}$ week. In team meeting group, patients got the chance to share their problems to a wide range of specialists. Comprehensive rehabilitation was facilitated by the participation of multiple healthcare providers, each with unique skills and training, to optimize function and improve the quality of life of the patients. The coordination and communication between patients and specialists helped to improve the functional status. As patients got the chance to meet with many specialists they became well well-motivated and well convinced to do their rehabilitation therapy and this could be another factor for better improvement in functional status.

A good collaboration of the various health care professionals within a team is seen as a key factor for an effective and efficient health care. ${ }^{6}$ Other studies also support the result. Rehabilitation teams were effective at improving the functional and psychosocial recovery of patients after stroke. ${ }^{17}$ Collaboratively, team working, particularly that which adopts an interdisciplinary approach, was found to be a key contributor to care quality in stroke services. ${ }^{18}$ Momsen et al reported that multidisciplinary rehabilitation team care effectively improves rehabilitation intervention. ${ }^{19}$

\section{Conclusion}

Rehabilitation team meeting significantly reduce disability of the patient. It needs to work continuously to build up the rehabilitation team to improve physical rehabilitation in Bangladesh to ensure total care of the disabled.

\section{Acknowledgment}

The authors are thankful to the patients and all team members who participated in this study.

\section{Conflict of interest: None}

Funding: Bangabandhu Sheikh Mujib Medical University (BSMMU), Dhaka, Bangladesh

Ethical approval: IRB of BSMMU, Dhaka

Submitted: $4^{\text {th } J u n e, ~} 2020$

Final revision received: $12^{\text {th }}$ November, 2020

Accepted: $25^{\text {th }}$ November, 2020

Published: $1^{\text {st }}$ December, 2020

\section{References}

1. WHO, 2030 Gimigliano F, Negrini S. The World Health Organization "rehabilitation 2030-a call for action". Eur J Phys Rehabil Med. 2017;53:155-68.

URL:www.who.int/rehabilitation/rehab-2030call-for-action/en/

2. King JC, Blankenship KJ, Schalla W, Mehta A. Rehabilitation team function and prescriptions, referrals and order writing. In: Firestein GS, Budd R, Gabriel SE, McInnes IB, O'Dell JR, editors. Kelley's Textbook of Rheumatology. $10^{\text {th }}$ ed. Philadelphia: Elsevier Health Sciences; 2017. p.357.

3. Norrefalk JR. How do we define multidisciplinary rehabilitation?. J Rehabil Med. 2003;35:100-1.

DOI: $10.1080 / 16501970306118$

4. Wagner EH. The role of patient care teams in chronic disease management. Brit Med J. 2000;320:569-72.

DOI: $10.1136 / \mathrm{bmj} .320 .7234 .569$

5. Davenport DL, Henderson WG, Mosca CL, Khuri SF, Mentzer RM. Risk-adjusted morbidity in teaching hospitals correlates with reported levels of communication and Collaboration on surgical teams but not with scale measures of teamwork climate, safety climate, or working conditions. J Amer Coll Surg. 2007;205:778-84.

DOI: 10.1016/j.jamcollsurg.2007.07.039

6. Lemieux-Charles L, McGuire WL. What do we know about health care team effectiveness? A 
review of the literature. Med Care Res Rev. 2006;63:263-300.

DOI:10.1177/1077558706287003

7. Grumbach K, Bodenheimer T. Can health care teams improve primary care practice? J Amer Med Assoc. 2004;291:1246-51.

DOI: $10.1001 /$ jama.291.10.1246.

8. Kushner DS, Peters KM, Johnson-Greene D. Evaluating use of the siebens domain management model during inpatient rehabilitation to increase functional independence and discharge rate to home in stroke patients. PM \& R. 2015;7:354-64.

DOI: $10.1016 /$ j.pmrj.2014.10.010.

9. Uddin T, Khasru MR, Islam MT, Emran MA, Rahman MS, Shakoor MA, Moyeenuzzaman M. Rehabilitation in Bangladesh. Phys Med Rehabil Clin N Am. 2019;30:795-805.

DOI: 10.1016/j.pmr.2019.07.005

10. Uddin T, Islam MT, Rathore FA, O'Connell C. Disability and rehabilitation medicine in Bangladesh: Current scenario and future perspectives. JISPRM. 2019;2:168.

DOI: $10.4103 /$ jisprm.jisprm_61_19

11. World Health Organization. WHO global disability action plan 2014-2015. Better health for all people with a disability. Geneva: WHO Press; 2015.

URL:www.who.int/disabilities/actionplan/en/. accessed October 20, 2018.

12. Linacre JM, Heinemann JW, Wright BD, Granger CV, Hamilton BB. The structure and stability of the functional independence measure. Arch Phys Med Rehabil. 1994;75:127-32.

DOI: $10.1016 / 0003-9993(94) 90384-0$

13. Quaschning K, Körner M, Wirtz M. Analyzing the effects of shared decision-making, empathy and team interaction on patient satisfaction and treatment acceptance in medical rehabilitation using a structural equation modeling approach. Patient Educ Coun. 2013;91:167-75.

DOI: $10.1016 /$ j.pec.2012.12.007

14. Population monograph of Bangladesh. Disability in Bangladesh: Prevalence and Pattern. 2015 Bangladesh Bureau of Statistics (BBS). Statistics and Informatics Division (SID). Ministry of Planning, Dhaka. 2015.

15. Mashreky SR, Rahman A, Khan TF, Faruque M, Svanström L, Rahman F. Hospital burden of road traffic injury: Major concern in primary and secondary level hospitals in Bangladesh. Public Health. 2010;124:185-9.

DOI: $10.1016 /$ j.puhe.2010.01.004

16. Saha UK, Alam MB, Rahman AK, Hussain AH, Mashreky SR, Mandal G, Mohammad QD. Epidemiology of stroke: findings from a community-based survey in rural Bangladesh. Public health. 2018;160:26-32.

DOI:10.1016/j.puhe.2018.03.024

17. Allen L, Richardson M, McIntyre A, Janzen S, Meyer M, Ure D, Willems D, Teasell R. Community Stroke Rehabilitation Teams: Providing Home-Based Stroke Rehabilitation in Ontario, Canada. Can J Neurol Sci. 2014;41:697703.

DOI: $10.1017 /$ cjn.2014.31

18. Clarke DJ, Forster A. Improving post-stroke recovery: the role of the multidisciplinary health care team. J Multidiscip Health. 2015;8:433.

DOI: $10.2147 /$ JMDH.S68764

19. Momsen AM, Rasmussen JO, Nielsen CV, Iversen MD, Lund H. Multidisciplinary team care in rehabilitation: an overview of reviews. J Rehabil Med. 2012;44:901-12. DOI: $10.2340 / 16501977-1040$ 